\title{
Sudden onset of sleep caused by hypothalamic infarction: a case report
}

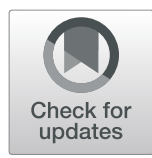

\author{
Takeo Matsubara ${ }^{1}, K^{2}$ eisuke Suzuki ${ }^{\text {* }}$ D, Akiko Kawasaki ${ }^{1}$, Masayuki Miyamoto², Madoka Okamura', \\ Takashi Kanbayashi ${ }^{3}$, Hidehiro Takekawa ${ }^{1,4,5}$, Toshiki Nakamura ${ }^{6}$, Yuji Watanabe', Masanori Matsubara ${ }^{1}$ and \\ Koichi Hirata'
}

\begin{abstract}
Background: Hypothalamic lesions, such as tumors and demyelinating diseases, reportedly cause abnormal sleepiness. However, stroke involving the hypothalamus has rarely been described. Here, we report a patient with infarction restricted to the hypothalamus who presented with sudden onset of sleep.

Case presentation: A 42-year-old woman with a history of migraine without aura presented with irresistible sleepiness and developed several episodes of sudden onset of sleep. Neurological examinations were unremarkable except for partial left Horner syndrome. Brain magnetic resonance imaging (MRI) revealed a high-intensity lesion restricted to the left hypothalamus on diffusion-weighted and fluid-attenuated inversion recovery MRI images. Cerebrospinal fluid (CSF) orexin-A levels obtained on hospital day 3 after her sleepiness had resolved were normal (337 pg/mL; normal > $200 \mathrm{pg} / \mathrm{mL}$ ). Serum anti-nuclear and anti-aquaporin 4 (AQP4) antibodies and CSF myelin basic protein and oligoclonal band were negative. A small hypothalamic infarction was suspected, and the patient was treated with intravenous edaravone and argatroban, as well as oral clopidogrel. Three months later, there had been no clinical relapse, and the hypothalamic lesion had almost disappeared on follow-up MRI. No new lesion suggestive of demyelinating disease or tumor was observed.
\end{abstract}

Conclusion: Hypothalamic stroke should be considered a cause of sudden onset of sleep.

Keywords: Hypothalamic infarction, Sudden onset of sleep, Hypersomnia, Horner syndrome

\section{Background}

The hypothalamus plays a key role in regulating sleep, wakefulness, temperature, and food intake. Hypothalamic lesions due to tumor and demyelinating diseases (e.g., multiple sclerosis and neuromyelitis optica spectrum disorders) reportedly cause abnormal sleepiness, and reduced orexin-A levels in the cerebrospinal fluid (CSF) have been observed in those patients, suggesting that an impaired orexinergic system participates in the development of hypersomnia [1]. We recently reported decreased CSF orexin levels in 3 of 4 central nervous system lupus patients with hypothalamic lesions and excessive daytime sleepiness [2]. However, hypersomnia following hypothalamic infarction has rarely

\footnotetext{
* Correspondence: keisuke@dokkyomed.ac.jp

${ }^{1}$ Department of Neurology, Dokkyo Medical University, 880 Kitakobayashi,

Mibu, Shimotsuga, Tochigi 321-0293, Japan

Full list of author information is available at the end of the article
}

been documented $[3,4]$. Herein, we present a patient with a history of migraine who developed several episodes of sudden onset of sleep due to a small infarct in the posterior medial part of the hypothalamus.

\section{Case presentation}

A 42-year-old woman noticed irresistible sleepiness around noon. On the same day, she developed sudden onset of sleep several times while standing as she visited her child's classroom. Each episode lasted for a few seconds. Excessive daytime sleepiness persisted throughout that day but resolved on the following day. The patient had quit smoking 10 years ago. The patient's sleep habits were regular; she slept $8 \mathrm{~h} /$ night from $11 \mathrm{PM}$ to $7 \mathrm{AM}$. The patient had been treated for migraine without aura for 24 years and had a history of surgical treatment for an ovarian cyst. The patient was not on regular medicine but took loxoprofen for migraine attacks. At the initial 
presentation, the patient was alert. The pupil sizes were asymmetric (right $4 \mathrm{~mm}$, left $2.5 \mathrm{~mm}$ ). The pupillary reflexes to light were normal, and left-sided ptosis was noted. There was no disturbance of sweating. Facial sensations and facial muscles were intact. No motor weaknesses or sensory disturbances were noted. Diffusionweighted (Fig. 1a) and fluid-attenuated inversion recovery magnetic resonance imaging (MRI) revealed a highintensity lesion restricted to the posterior part of the left hypothalamus (Fig. 1b, c, f). Magnetic resonance angiography showed no stenosis or occlusion in the main cerebral arteries. Atherosclerotic changes were unremarkable on carotid artery sonography. An electrocardiogram showed normal tracing. On transthoracic and transesophageal echocardiography, a potential cardiac source of an embolism or the right-to-left shunt, including patent foramen ovale, was not detected. On laboratory exams, liver function, renal function, glucose, cholesterol, soluble interleukin-2 receptor, c-reactive protein, erythrocyte sedimentation rate, homocysteine, protein C, protein S, antithrombin III, prothrombin time, activated partial thromboplastin time and D-dimer levels $(0.8 \mu \mathrm{g} /$ $\mathrm{ml}$ ) were normal. The levels of pituitary hormones, such as thyroid stimulating hormone, adrenocorticotropic hormone, follicle stimulating hormone, luteinizing hormone, growth hormone, and prolactin, were normal.
Anti-nuclear antibody, anti-SS-A/B antibody, MPOANCA, and $\beta$-2-glycoprotein I were all negative. CSF analysis was normal (2 mononuclear cells/ $\mu \mathrm{L}$ and a protein level of $33 \mathrm{mg} / \mathrm{dL}$ ). CSF orexin-A levels obtained on hospital day 3 were normal $(337 \mathrm{pg} / \mathrm{mL}$; normal $>200$ $\mathrm{pg} / \mathrm{mL}$ ). Serum anti-aquaporin 4 (AQP4) antibody, CSF myelin basic protein and oligoclonal band were negative. Electroencephalography showed a background of 10-11 $\mathrm{Hz}$ alpha rhythms without epileptic discharges. A small infarction restricted to the hypothalamus was suspected, and the patient was treated with intravenous edaravone and argatroban, as well as oral clopidogrel. She did not complain of recurrence of sleepiness after admission. Her eye symptoms spontaneously improved on hospital day 2. Three months later, there had been no clinical relapse, and follow-up MRI was performed. Diffusionweighted imaging was unremarkable (Fig. 1d), and fluidattenuated inversion recovery MRI showed reduced intensity of the hypothalamic lesion (Fig. 1e). There was no new lesion suggestive of demyelinating disease or tumor.

\section{Discussion and conclusions}

Our patient exhibited several short episodes of sudden onset of sleep and partial Horner syndrome due to a small infarct in the unilateral hypothalamus. In our

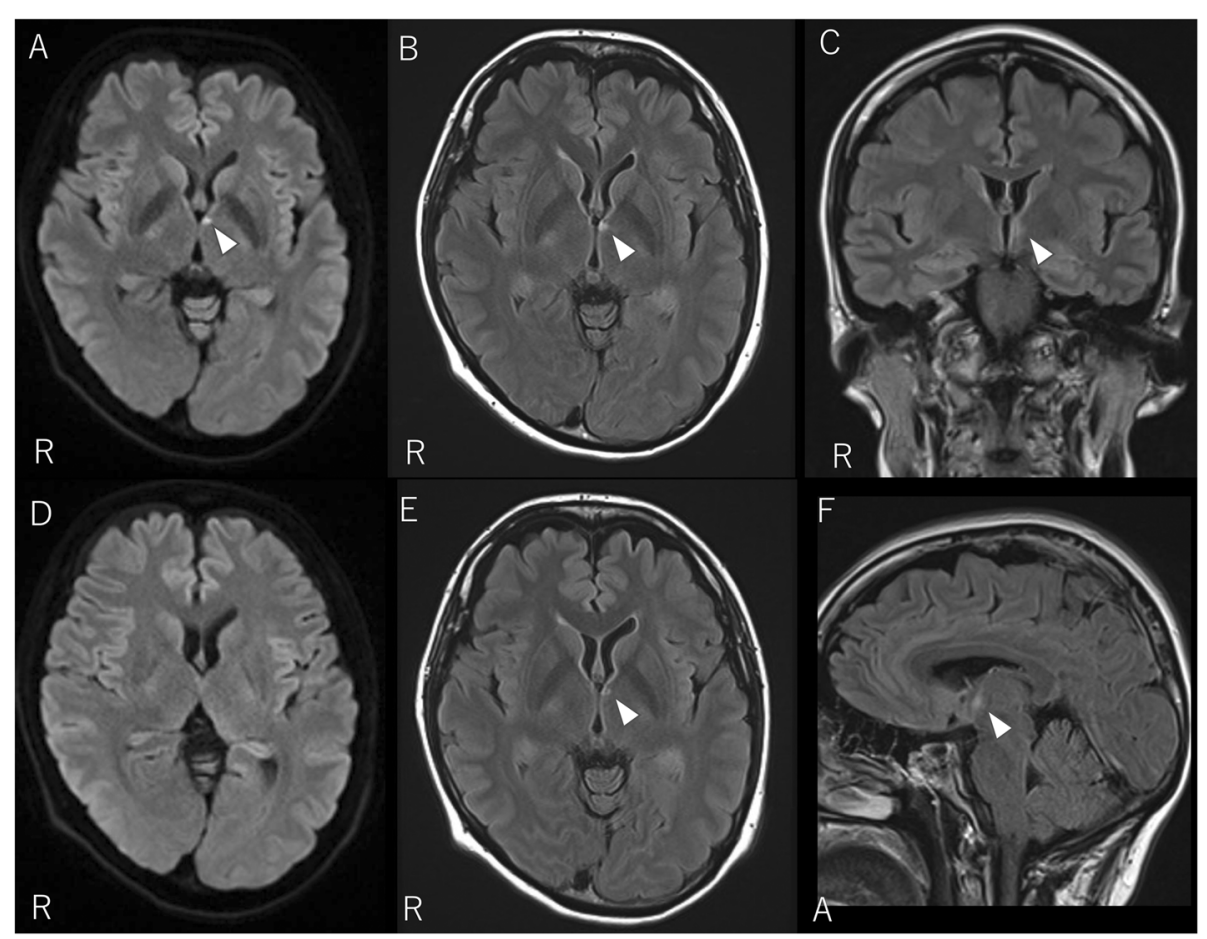

Fig. 1 Brain MRI of the patient. Diffusion-weighted (a) and fluid-attenuated inversion recovery MRI images (b, c) obtained on admission reveal a small, high-signal intensity restricted to the left hypothalamus (arrowheads). Sagittal fluid-attenuated inversion recovery MRI shows involvement of the posterior part of the hypothalamus (f, arrowhead). Follow-up MRI after 3 months shows unremarkable findings on diffusion-weighted images (d) and reduced intensity of the hypothalamic lesion on fluid-attenuated inversion recovery MRI images (e) (arrowhead) 
patient, left-sided ptosis was considered partial Horner syndrome rather than incomplete oculomotor nerve palsy because there was no limitation of extraocular movement and the ipsilateral pupil was smaller $(2.5 \mathrm{~mm})$ than the contralateral pupil $(4 \mathrm{~mm})$. Horner syndrome due to hypothalamic stroke has been previously reported $[3,5,6]$. Isolated hypothalamic infarction is rare because of the rich vascular supply and anastomosis of this region. In a study examining anastomoses among the hypothalamic arteries in 14 human brains, there were 5 to 22 channel-like anastomoses on either side of the brain. The anastomoses most often involved were the commissural arteries, superior hypophyseal arteries and the tuberoinfundibular branches of the posterior communicating artery [7]. We summarized the characteristics of 6 patients with hypothalamic stroke with or without hypersomnia, including our patient (Table 1) $[3-6,8]$. The size of the hypothalamic lesion of our patient was as small as that of a patient reported by Smith et al. [8] but was significantly smaller than those of other patients [3-6]. Three of 6 (50\%) patients exhibited hypersomnia, and CSF orexin levels were measured in 2 of those 3 patients. Scammell et al. [4] reported that a 23-year-old man developed hypersomnia and cataplexy following bilateral hypothalamic infarctions after removal of craniopharyngioma. Short sleep latency, sleep-onset rapid eye movement (REM) periods and reduced CSF orexin-A levels $(167 \mathrm{pg} / \mathrm{ml})$ led to a diagnosis of narcolepsy secondary to hypothalamic stroke. In our patient who presented with several episodes of sudden onset of sleep, the CSF orexin-A level was within the normal range $(337 \mathrm{pg} / \mathrm{ml})$. Moreover, the lesion on the MRI images was small and confined to the left medial to posterior hypothalamus in our patient. A possible reason for the normal CSF orexin-A level in our patient was that she had no sleepiness at the time of the CSF examination; therefore, it is possible that the posterolateral parts of the hypothalamus may have been more extensively involved at the initial onset. Additionally, arousal systems other than the orexinergic system, such as histaminergic tuberomammillary neurons, may have been involved. In a study including 6 patients with bilateral paramedian thalamic infarctions, CSF orexin-A levels were decreased in 2 patients with rostral midbrain involvement and were within normal ranges in 4 patients without midbrain involvement [9]. Hypersomnia in paramedian thalamic stroke is known as "pseudohypersomnia", characterized by increased stage N1, decreased stage N2 and spindles during sleep; however, REM sleep is unaffected $[10,11]$.

The etiology of stroke in our patient is unclear. The patient had no vascular risk factors, such as hypertension, dyslipidemia or diabetes, and had quit smoking 10 years before. There were no atherosclerotic changes on carotid artery sonography, coagulation abnormalities or antibodies related to central nervous system vasculitis on laboratory testing. Large vessel vasculitis, such as Takayasu's arteritis and temporal arteritis, were unlikely

Table 1 Characteristics of patients with hypothalamic stroke with and without hypersomnia

\begin{tabular}{|c|c|c|c|c|c|c|}
\hline Patient no. & Present case & Bassetti et al. [5] & Austin et al. [3] & $\begin{array}{l}\text { Stone et al. } \\
{[6]}\end{array}$ & Smith et al. [8] & Scammell et al. [4] \\
\hline $\begin{array}{l}\text { Age (years)/ } \\
\text { Sex }\end{array}$ & $42 / F$ & $36 / M$ & $62 / F$ & $67 / M$ & $40 / M$ & $23 / M$ \\
\hline Hypersomnia & + & - & + & - & - & + \\
\hline $\begin{array}{l}\text { Other clinical } \\
\text { features }\end{array}$ & Left ptosis & Right Horner syndrome & $\begin{array}{l}\text { Left-sided occipital } \\
\text { headache, left-sided } \\
\text { ptosis, and right-sided } \\
\text { face and arm } \\
\text { weakness }\end{array}$ & $\begin{array}{l}\text { Right arm } \\
\text { weakness, } \\
\text { right Horner } \\
\text { syndrome }\end{array}$ & $\begin{array}{l}\text { Hyperhidrosis } \\
\text { on the left } \\
\text { face, arm, } \\
\text { chest, } \\
\text { abdomen, and leg }\end{array}$ & $\begin{array}{l}\text { Gonadal hypoplasia and } \\
\text { delayed puberty. }\end{array}$ \\
\hline Habits & $\begin{array}{l}\text { Quit smoking } \\
\text { and drinking } \\
10 \text { years ago }\end{array}$ & Not available & Not available & Not available & No smoking & Not available \\
\hline $\begin{array}{l}\text { Comorbid } \\
\text { diseases/past } \\
\text { medical } \\
\text { history }\end{array}$ & $\begin{array}{l}\text { Migraine } \\
\text { without aura }\end{array}$ & Not available & $\begin{array}{l}\text { Diabetes mellitus, } \\
\text { hypertension, } \\
\text { coronary artery } \\
\text { disease }\end{array}$ & Not available & $(-)$ & $\begin{array}{l}\text { A large } \\
\text { craniopharyngioma was } \\
\text { identified below his } \\
\text { posterior hypothalamus } \\
\text { and was surgically } \\
\text { removed. }\end{array}$ \\
\hline $\begin{array}{l}\text { Hypothalamic } \\
\text { lesions on MRI }\end{array}$ & $\begin{array}{l}\text { The left } \\
\text { posterolateral } \\
\text { part of } \\
\text { hypothalamus }\end{array}$ & $\begin{array}{l}\text { The occipital lobe, } \\
\text { inferomedial temporal lobe, } \\
\text { anterolateral midbrain and } \\
\text { ventroposterolateral thalamo- } \\
\text { subthalamic area }\end{array}$ & $\begin{array}{l}\text { The left posterior } \\
\text { hypothalamus, the } \\
\text { genu and posterior } \\
\text { limb of the internal } \\
\text { capsule. }\end{array}$ & $\begin{array}{l}\text { The left } \\
\text { hypothalamus } \\
\text { and anterior } \\
\text { thalamus }\end{array}$ & $\begin{array}{l}\text { The right } \\
\text { posterior } \\
\text { hypothalamus }\end{array}$ & $\begin{array}{l}\text { The bilateral, nearly entire, } \\
\text { hypothalamus }\end{array}$ \\
\hline $\begin{array}{l}\text { CSF orexin-A } \\
\text { levels }(\mathrm{pg} / \mathrm{ml})\end{array}$ & 337 & Not available & Not available & Not available & Not available & 167 \\
\hline
\end{tabular}


as inflammatory markers (c-reactive protein and erythrocyte sedimentation rate) were not elevated. The patient had migraine, but this event was not accompanied by a preceding aura, which is a risk factor for stroke among young individuals [12]. Patent foramen ovale was not found, and cardiac and aortic sources of embolism were unlikely based on transthoracic and transesophageal echocardiography. However, in our patient, artery-to-artery embolism, arterial dissection without headache, primary angiitis of the central nervous system or intravascular lymphoma with normal serum soluble interleukin-2 receptor could not be completely ruled out.

As a limitation, we did not perform polysomnography or multiple sleep latency tests to evaluate the patient's sleep structure and abnormal sleepiness because abnormal sleepiness and sudden onset of sleep had resolved just before admission. Additionally, the CSF orexin measurement was performed after recovery from abnormal sleepiness.

In conclusion, we reported a patient with hypothalamic infarction who presented with sudden onset of sleep and hypersomnia. Thus, hypothalamic stroke should be considered a cause of sudden onset of sleep.

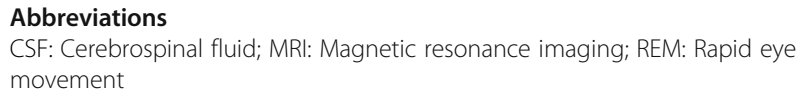

\section{Acknowledgments}

We thank Drs Kentaro lizuka and Narihiro Nozawa from the Department of Neurology, Dokkyo Medical University, for their help with this study. We wish to thank the patient for participating in this study.

\section{Authors' contributions}

All authors have read and approved the manuscript and contributed to the design of the study and interpretation of data. TM and KS drafted the manuscript and contributed to the diagnosis and treatment of the patient. AK, MO, YW, and M. Matsubara contributed to the diagnosis and treatment of the patient. TK contributed to the CSF measurement of orexin-A and critical revision of the manuscript. M. Miyamoto, HT, TN and KH critically revised the manuscript.

\section{Funding}

None.

\section{Availability of data and materials}

All data collected by clinical examination, laboratory and imaging data, and a review of the patient's medical record are presented in the manuscript.

\section{Ethics approval and consent to participate}

Not applicable.

\section{Consent for publication}

Written informed consent was obtained from the patient included in the study.

\section{Competing interests}

Keisuke Suzuki is an editorial board member of BMC Neurology. The authors declare no potential conflicts of interest in relation to this article.

\section{Author details}

'Department of Neurology, Dokkyo Medical University, 880 Kitakobayashi, Mibu, Shimotsuga, Tochigi 321-0293, Japan. ${ }^{2}$ Department of Clinical Medicine for Nursing, Dokkyo Medical University School of Nursing, Tochigi, Japan.
${ }^{3}$ International Institute for Integrative Sleep Medicine (WPI-IIIS), University of Tsukuba, Tsukuba, Japan. ${ }^{4}$ Center of Medical Ultrasonics, Dokkyo Medical University Hospital, Tochigi, Japan. ${ }^{5}$ Stroke Center, Dokkyo Medical University Hospital, Tochigi, Japan. ${ }^{6}$ Department of Neurology, Rehabilitation Amakusa Hospital, Saitama, Japan.

Received: 12 March 2019 Accepted: 25 July 2019

Published online: 02 August 2019

\section{References}

1. Kanbayashi T, Sagawa Y, Takemura F, Ito SU, Tsutsui K, Hishikawa Y, Nishino $\mathrm{S}$. The pathophysiologic basis of secondary narcolepsy and hypersomnia. Curr Neurol Neurosci Rep. 2011;11(2):235-41.

2. Suzuki K, Miyamoto M, Miyamoto T, Matsubara T, Inoue Y, lijima M, Mizuno S. Horie J, Hirata K, Shimizu T, et al. Cerebrospinal fluid orexin-a levels in systemic lupus erythematosus patients presenting with excessive daytime sleepiness. Lupus. 2018;27(11):1847-53.

3. Austin CP, Lessell S. Horner's syndrome from hypothalamic infarction. Arch Neurol. 1991;48(3):332-4.

4. Scammell TE, Nishino S, Mignot E, Saper CB. Narcolepsy and low CSF orexin (hypocretin) concentration after a diencephalic stroke. Neurology. 2001; 56(12):1751-3.

5. Bassetti C, Staikov IN. Hemiplegia vegetativa alterna (ipsilateral Horner's syndrome and contralateral hemihyperhidrosis) following proximal posterior cerebral artery occlusion. Stroke. 1995;26(4):702-4.

6. Stone WM, de Toledo J, Romanul FC. Horner's syndrome due to hypothalamic infarction. Clinical, radiologic, and pathologic correlations. Arch Neurol. 1986;43(2):199-200.

7. Marinkovic SV, Milisavljevic MM, Marinkovic ZD. Microanatomy and possible clinical significance of anastomoses among hypothalamic arteries. Stroke. 1989:20(10):1341-52

8. Smith CD. A hypothalamic stroke producing recurrent hemihyperhidrosis. Neurology. 2001;56(10):1394-6.

9. Suzuki K, Miyamoto T, Miyamoto M, Maeda H, Nokura K, Tohyama J, Hirata K, Shimizu T, Kanbayashi T. Hypocretin-1 levels in the cerebrospinal fluid of patients with Percheron artery infarction with or without midbrain involvement: a case series. Medicine (Baltimore), 2016:95(29):e4281.

10. Bassetti C, Mathis J, Gugger M, Lovblad KO, Hess CW. Hypersomnia following paramedian thalamic stroke: a report of 12 patients. Ann Neurol. 1996;39(4):471-80.

11. Hermann DM, Siccoli M, Brugger $P$, Wachter $K$, Mathis J, Achermann $P$, Bassetti CL. Evolution of neurological, neuropsychological and sleep-wake disturbances after paramedian thalamic stroke. Stroke. 2008;39(1):62-8.

12. Abanoz Y, Gulen Abanoz Y, Gunduz A, Uluduz D, Ince B, Yavuz B, Goksan B. Migraine as a risk factor for young patients with ischemic stroke: a casecontrol study. Neurol Sci. 2017;38(4):611-7.

\section{Publisher's Note}

Springer Nature remains neutral with regard to jurisdictional claims in published maps and institutional affiliations.
Ready to submit your research? Choose BMC and benefit from:
- fast, convenient online submission
- thorough peer review by experienced researchers in your field
- rapid publication on acceptance
- support for research data, including large and complex data types
- gold Open Access which fosters wider collaboration and increased citations
- maximum visibility for your research: over $100 \mathrm{M}$ website views per year
At BMC, research is always in progress.
Learn more biomedcentral.com/submissions 